\title{
ELABORACIÓN DE HELADO CON DIFERENTES CONCENTRACIONES DE LECHE DE SOYA (Glycine max)
}

\author{
ICE CREAM PROCESSING WITH DIFFERENT \\ CONCENTRATIONS OF SOY MILK (Glycine max)
}

\author{
Silvia Liseth Palma-Santana, Jennifer Paulina Espinoza Zambrano, Luis Eduardo Flores-Holguín, \\ Kathya Sayonara Reyna-Arias
}

Universidad Laica Eloy Alfaro de Manabí. Av. Circunvalación - Vía a San Mateo, Manta - Manabí - Ecuador

Email: kathya.reyna@uleam.edu.ec

\section{Información del articulo}

Tipo de artículo: Artículo original

Recibido:

02/06/2020

Aceptado:

28/12/2020

Licencia:

CC BY-NC-SA 4.0

Revista

ESPAMCIENCIA

11(2):120-130

DOI:

https://doi.org/10.51

260/revista_espamci

encia.v11i2.199

\begin{abstract}
Resumen
La leche de soya proviene de una leguminosa rica en proteínas y constituye una materia prima con alto valor nutricional en alimentos procesados. En el presente estudio se utilizó la leche de soya para elaborar helados en diferentes dosis: $20 \%, 40 \% 60 \%$ y $80 \%$, almacenado a una temperatura de $-15^{\circ} \mathrm{C}$ por un período de 30 días. Se determinó las características físico-químicas, sensoriales y microbianas de los helados elaborados a base de leche de soya. El análisis sensorial con 16 voluntarios seleccionó el helado con $20 \%$ de leche de soya como mejor tratamiento, obteniendo como resultado en los días de estudios $1,10,20$ y 30 , un pH de 5,22 , solidos solubles de $30{ }^{\circ}$ Brix y en cuanto a la acidez titulable de $0,40 \%$, y un contenido aceptable en proteínas del 2,05\%, materia grasa $2,78 \%$, sólidos totales $28,5 \%$ y de carbohidratos $29,17 \%$. Los análisis microbianos en mohos fueron de <1x10 UFC/g, levaduras 2,95 Log $10 \mathrm{UFC} / \mathrm{g}$, coliformes totales 1,95 Log $10 \mathrm{UFC} / \mathrm{g}$, recuentos aerobios 3,54 Log $10 \mathrm{UFC} / \mathrm{g}$. El costo del mejor tratamiento de helado a base de leche de soya es de $\$ 1,14$ dólares por litro.
\end{abstract}

Palabras clave: Helado, soya, nutricional, proteínas, alimento.

\begin{abstract}
Soy milk comes from a protein-rich legume and is a raw material with high nutritional value in processed foods. In this study, soy milk was used to make ice cream in different doses: $20 \%, 40 \% 60 \%$ and $80 \%$, stored at a temperature of $-15^{\circ} \mathrm{C}$ for a period of 30 days. The physical-chemical, sensory and microbial characteristics of ice cream made from soy milk were determined. The sensory analysis with 16 volunteers selected the ice cream with $20 \%$ of soy milk as the best treatment, obtaining as a result in the days of studies 1, 10, 20 and 30, a pH of 5.22, soluble solids of $30{ }^{\circ}$ Brix and in terms of titratable acidity of $0.40 \%$, and an acceptable content in protein of $2.05 \%$, fat $2.78 \%$, total solids $28.5 \%$ and carbohydrates $29.17 \%$. Microbial analyses on moulds were $<1 \times 10 \mathrm{CFU} / \mathrm{g}$, yeasts $2.95 \mathrm{Log} 10 \mathrm{CFU} / \mathrm{g}$, total coliforms $1.95 \mathrm{Log} 10 \mathrm{CFU} / \mathrm{g}$, aerobic counts $3.54 \mathrm{Log} 10 \mathrm{CFU} / \mathrm{g}$. The cost of the best soy milk based ice cream treatment is $\$ 1.14$ per litre.
\end{abstract}

Keywords: Ice cream, soy, nutritional, protein, food

\section{INTRODUCCIÓN}

El Ecuador es un país que cuenta con diversidad de frutas, hortalizas, leguminosas, debido a las buenas condiciones climáticas (Miranda et al., 2019), razón por la cual se ubica en un lugar de privilegio para el sector agroindustrial, actividad que reúne las condiciones para convertirse en uno de los ejes de desarrollo social y de gran aporte para nuestra economía.
Farías (2017) menciona que es una necesidad descubrir nuevas fuentes nutricionales para las regiones donde la variedad y cantidad de alimento son inadecuadas, esto ha hecho necesario desarrollar técnicas y procesos que permitan utilizar los recursos disponibles para producir alimentos altamente proteicos. Donde muchos productores emplean leche de soya para la creación de nuevos productos alimenticios. 
La leche de soya cobra un papel muy importante en la nutrición de los consumidores, siendo una opción para adquirir proteínas y otros nutrientes. Además, es una alternativa de consumo para la población adulta de países como Asia, Europa y América Latina que son intolerantes a la lactosa (Benítez, 2006).

Salazar (2012) indica que la leche de soya es uno de los mayores aliados si se requiere enriquecer la alimentación y evitar problemas de salud. Esta se elabora de una proteína vegetal de gran calidad nutritiva que a la vez es buena fuente de proteínas también presente en la leche de vaca, huevos, carne y pescado; se la obtiene del remojo, trituración, cocción y filtrado de las semillas de soya (Tripathi y Misra, 2005).

Sin embargo, Tobar (2008), menciona que la leche de soya elaborada industrialmente tiene mayor contenido de grasa y menos contenido proteico, mientras que la leche de soya artesanal es más nutritiva y económica, para los consumidores pues obtienen un ahorro del $30-40 \%$ por cada litro de soya.

Para Constante (2012) el método más apropiado de conservación de la leche y yogurt de soya es el uso de benzoato de sodio al $0,5 \%$, el cual no afecta a las características nutritivas, logrando en la leche un periodo de vida útil de 15 días y en el yogurt un periodo de 30 días, inhibiendo en este periodo el crecimiento de la mayoría de los microorganismos.

En efecto, Gómez (2011), demostró la gran aceptación de la leche de soya por parte de los consumidores pudiendo incorporar productos nuevos en el mercado que cumplan las expectativas de los clientes.

El objetivo principal de este estudio fue elaborar helados con diferentes dosificaciones de leche de soya y determinar el mejor tratamiento como alternativa de desarrollo comercial del medio, reduciendo grasa y mejorando la calidad proteica en su composición, beneficiando a los consumidores M'Boumba et al (2009), con una buena fuente de fósforo, potasio, vitaminas del Grupo B, zinc, hierro y la vitamina E (Benítez 2006), además es la única legumbre que contiene los diez aminoácidos esenciales en la proporción correcta para la salud humana.

\section{MATERIALES Y MÉTODOS}

El estudio se realizó en los laboratorios de Procesos Agroindustriales de la Facultad Ciencias Agropecuarias de la Universidad Laica Eloy Alfaro de Manabí, ubicado en la ciudad de Manta, Av. Circunvalación -Vía a San Mateo, Manta-Manabí- Ecuador.

\section{Proceso de elaboración de los helados a base de leche de soya}

Se empleó moras frescas para saborizar el helado, las mismas que fueron acondicionadas para posteriormente obtener la pulpa del fruto, utilizando una licuadora marca Black \& Decker MOD. BLM10350MN y un colador para retener los residuos de semillas presentes en la fruta. La pulpa fue pasteurizada a $85^{\circ} \mathrm{C}$ por $10 \mathrm{~min}$; para destruir los microorganismos patógenos presentes y por último se dejó enfriar a temperatura de $5^{\circ} \mathrm{C}$.

Para la obtención de la leche de soya se realizó una recepción, pesado, selección y limpieza de los granos.

Posteriormente se preparó los granos de soya remojándolos en agua a $10^{\circ} \mathrm{C}$, usando tres veces el peso del grano, en un tiempo de 10 horas; transcurrido este tiempo se escaldó el grano remojado a una temperatura entre los 95 a $100^{\circ} \mathrm{C}$ por 5 minutos, teniendo como objetivo desactivar la enzima lipoxigenasa.

La molienda del grano se realizó con agua a $45^{\circ} \mathrm{C}$ en una licuadora, en la misma proporción peso/volumen (1 libra de soya/1 litro de agua). Después de licuar los granos de soya, se procedió a la pasteurización de la leche a una temperatura de $75^{\circ} \mathrm{C}$ por 15 minutos y por último un enfriamiento a temperatura de $5^{\circ} \mathrm{C}$.

\section{Proceso de elaboración}

Para la elaboración de las diferentes formulaciones experimentales se siguió el proceso detallado en la figura1.

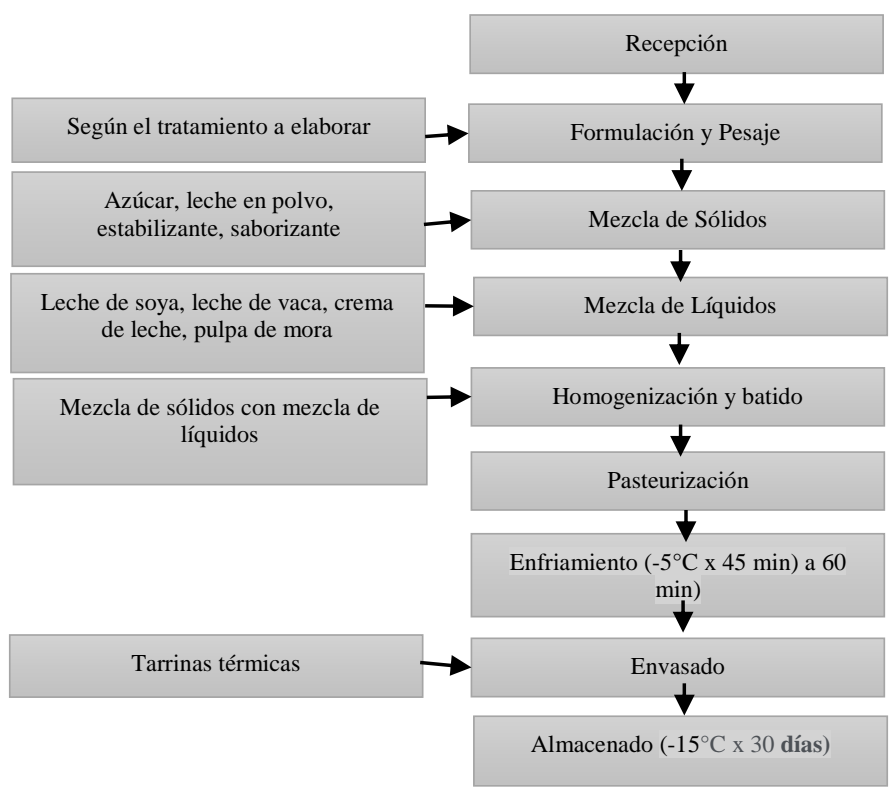

Figura 1. Flujograma del proceso de elaboración de los helados a base de leche soya 
Para la elaboración de los helados a base de soya se realizó la recepción de todos los ingredientes a utilizar en la preparación de la mezcla, luego se seleccionó los insumos, y se procedió al pesado de los mismos de acuerdo a la formulación, en una balanza analítica ADAM (max 250 $\mathrm{g}=0,0001 \mathrm{~g})$. En esta etapa se procedió a homogenizar todos los ingredientes sólidos (azúcar, leche en polvo, saborizante, estabilizante) en 2 min y los ingredientes líquidos (leche de soya, leche de vaca, pulpa de mora, crema de leche, etc.), agitándose hasta obtener una consistencia homogénea, mezclando los ingredientes sólidos y líquidos con agitación constante para evitar la formación de grumos durante 6 minutos. Se usó una batidora de mano de 240W 5 velocidades 2499013000 Oster.

Las porciones de ingredientes empleados en la elaboración de los helados a base de soya se indican en el cuadro 1 .

Cuadro 1. Formulaciones de los tratamientos

\begin{tabular}{|c|c|c|c|c|c|}
\hline Formulación & & $\begin{array}{c}80 \% \text { leche de soya y } \\
20 \% \text { leche de vaca } \\
\text { (LS1V) } \\
\end{array}$ & $\begin{array}{c}60 \% \text { leche de soya y } \\
40 \% \text { leche de vaca } \\
\text { (LS2V) } \\
\end{array}$ & $\begin{array}{c}40 \% \text { leche de soya y } \\
60 \% \text { leche de vaca } \\
\text { (LS3V) } \\
\end{array}$ & $\begin{array}{c}20 \% \text { leche de soya y } \\
80 \% \text { leche de vaca } \\
\text { (LS4V) }\end{array}$ \\
\hline Ingredientes & Ud. & Peso & Peso & Peso & Peso \\
\hline Leche de soya & $\mathrm{ml}$ & 1500 & 1250 & 750 & 500 \\
\hline Leche de vaca & $\mathrm{ml}$ & 500 & 750 & 1250 & 1500 \\
\hline Leche evaporada & $\mathrm{ml}$ & 100 & 100 & 100 & 100 \\
\hline Crema de leche & $\mathrm{ml}$ & 200 & 200 & 200 & 200 \\
\hline Pulpa de mora & $\mathrm{ml}$ & 500 & 500 & 500 & 500 \\
\hline Saborizante de mora & $\mathrm{g}$ & 4,7 & 4,7 & 4,7 & 4,7 \\
\hline Azúcar & g & 1000 & 1000 & 1000 & 1000 \\
\hline Leche en polvo & g & 60 & 60 & 60 & 60 \\
\hline Estabilizante Homogel & g & 7 & 7 & 7 & 7 \\
\hline
\end{tabular}

Luego se procedió a pasteurizar hasta alcanzar una temperatura de $80^{\circ} \mathrm{C}$ en 5 minutos, el cual se incorporó la mezcla de los helados, a la máquina heladera Soft TAYLOR, en un tiempo de $45 \mathrm{~min}$ a $60 \mathrm{~min}$, dependiendo el porcentaje de leche de soya que contenga la mezcla, el envasado se lo realizó en tarrinas y se almacenó a una temperatura de $-15^{\circ} \mathrm{C}$ por 30 días.

\section{Caracterización sensorial de los helados}

Como primera etapa del estudio, se evaluaron características sensoriales de los helados a base de soya con 30 jueces voluntarios no entrenados, con base en la metodología indicada por Chacón et al. (2016), para los voluntarios calificadores con una escala hedónica de 4 puntos en la cual indicaron cuánto les gustó el helado, donde 1 es menos agradable y 5 más agradable, sin conocer previamente la composición del mismo.

\section{Caracterización físico-químico y microbiológico}

Se realizó muestras por triplicado de los helados determinando el contenido de $\mathrm{pH}$, grados Brix ( ${ }^{\circ} \mathrm{Brix}$ ), acidez titulable, solidos solubles, sobre aumentó overrum, solidos totales, contenido de grasa método AOAC 954, proteína con técnica kjeldahl y carbohidratos totales método del fenol-sufúrico, con base en los métodos establecidos en las diferentes Normas Ecuatorianas (NTE INEN 0014 (1984), ISO 3728 (2004), NTE INEN 0706 (2005), NTE INEN 0016 (1984)). Los grados Brix se midieron con un refractómetro modelo 140-117-556 de Vimael S.A.

Con las muestras obtenidas se realizó análisis microbiológicos para cuantificación en placas Petrifilm de unidades Log-UFC/g (Logaritmo-Unidades formadoras de colonias/ gramos) de mohos, levaduras, coliformes totales y aerobios con base en metodología y criterios establecidos en Normas Ecuatoriana, para garantizar la inocuidad de los helados elaborados a base de soya (NTE INEN 1 529-11 (1998), ISO 6611 (2004), NTE INEN 1 529-7 (2013), ISO 4832 (2006), NTE INEN 1529-5 (2006), ISO 4833-1 (2013)).

\section{Análisis estadístico de los datos}

Los datos obtenidos de las diferentes caracterizaciones nutricionales se analizaron con una prueba de comparación de medias por tukey $(p \leq 0,05)$ con el programa InfoStat 2016 versión 11.17. Los datos obtenidos en el análisis sensorial se presentan en gráfica como lo indica Chacón et al. (2016).

\section{Análisis económico o estimación económica}

El costo de tratamiento se determinó sumando todos los gastos generados en la producción de las muestras en estudio. Logrando así obtener el valor de gasto en la elaboración de cada tratamiento. 


\section{RESULTADOS Y DISCUSIÓN}

\section{Caracterización sensorial de los helados a base de soya de los tratamientos}

En cuanto al análisis organoléptico en la Gráfico 1, se observan los resultados brindados por los panelistas donde indica que existió una mejor aceptación y calificación hacia el tratamiento LS4V (20\% de soya y el $80 \%$ de leche de vaca), que en los otros tratamientos, con un número de aceptación de 16 panelistas, siguiendo el tratamiento LS3V (40\% de soya y el $60 \%$ de leche de vaca), con la aceptación de 7 panelistas, sucesivamente el tratamiento LS1V ( $80 \%$ de soya y el $20 \%$ de leche de vaca), con la aceptación de 4 panelistas y como el menos agradable se encontró el tratamiento LS2V (60\% de soya y el $40 \%$ de leche de vaca), con la aceptación de 3 panelistas. En el análisis estadístico se determinó que si hay diferencia significativa entre los tratamientos.

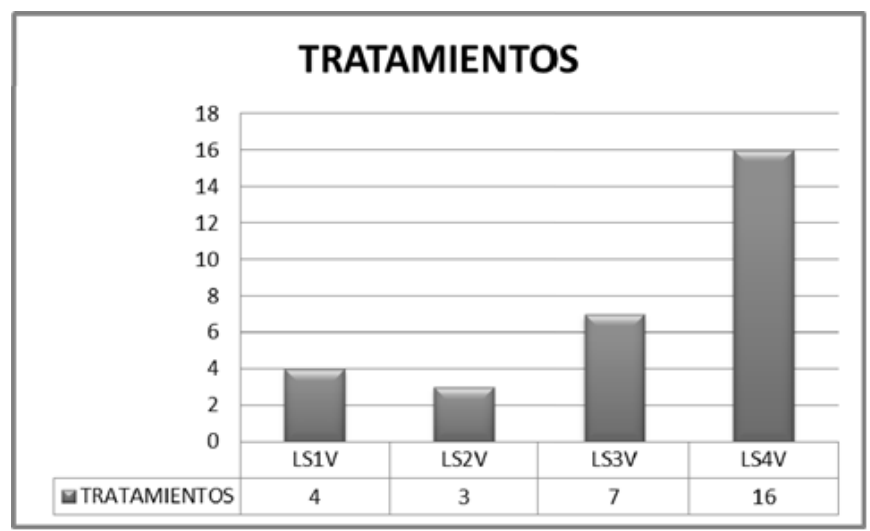

Gráfico 1. Análisis sensorial de los helados a base de leche de soya en un grupo de 30 jueces de panelistas no entrenados.

Según Ávalos (2018) en la práctica, un análisis organoléptico es una prueba de degustación o cata para determinar la calidad del producto. Correlaciona con Sancho et al. (1999) que la valoración sensorial es una función que la persona realiza desde la infancia y que la lleva, consciente o inconscientemente, a aceptar o rechazar los alimentos de acuerdo con las sensaciones experimentadas al observarlos o ingerirlos.

Al analizar los datos estadísticos de los análisis de evaluación sensorial, se puede certificar que los jueces detectaron diferencia significativa entre los tratamientos, escogiendo al tratamiento LS4V como el más preferido, deduciendo que, mientras mayor porcentaje de leche de soya presenta el helado, los jueces detectaban más el sabor de legumbre.

\section{Caracterización físico-químico de todos los tratamientos}

Se realizó análisis de $\mathrm{pH},{ }^{\circ}$ Brix, y acidez a cada uno de los tratamientos el primer día de almacenamiento a una temperatura de $-15^{\circ} \mathrm{C}$, antes de ser evaluados sensorialmente.

pH

En el gráfico 3 se observa el resultado promedio de los valores del $\mathrm{pH}$ de los diferentes tratamientos de helado con relación a las diferentes dosis de leche de soya y leche de vaca, en lo cual se determinó que el promedio mayor es el tratamiento LS1V (80\% leche de soya y $20 \%$ leche de vaca) con un resultado de 5,07 y los promedios menores de los tratamientos LS3V (40\% leche de soya y $60 \%$ leche de vaca) y LS4V (20\% leche de soya y $80 \%$ leche de vaca) con un promedio de 5,05.

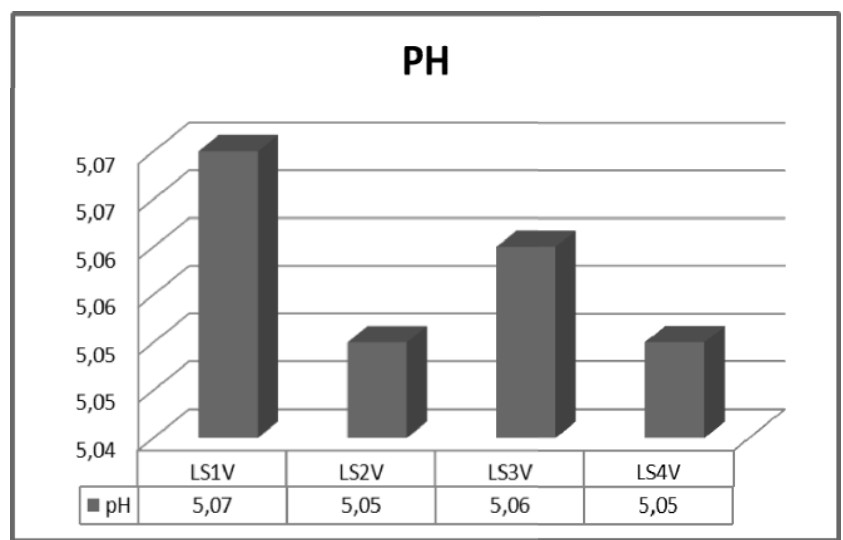

Gráfico 2. pH de las diferentes formulaciones de helados a base de leche de soya.

Al respecto el $\mathrm{pH}$ es un análisis importante de realizar ya que sirve como un indicador del estado general del producto, debido a que tiene influencia en múltiples procesos de alteración y estabilidad de los alimentos, así como la proliferación de microorganismos González (2011). Además, el pH de una mezcla de helado es generalmente de 5,4 a 7 aproximadamente Villalobos (2016), Sharma et al (2009). Como el pH es un factor primordial, se requiere obtener un tratamiento que mantenga el helado a base de leche de soya con un $\mathrm{pH}$ moderado, por lo cual todos los tratamientos cumplen con los valores que requiere la mezcla.

\section{Grados ${ }^{\circ} b r i x$}

Se determinó que el promedio mayor es el tratamiento LS4V (20\% leche de soya y $80 \%$ leche de vaca) con un promedio 31,67 y el promedio menor es el tratamiento LS1V (80\% leche de soya y $20 \%$ leche de vaca) con un promedio 29,67. 


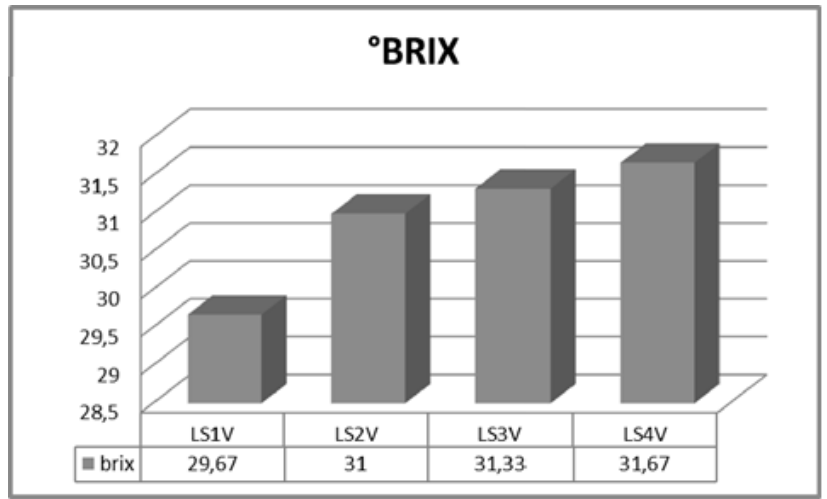

Gráfico 3. ${ }^{\circ}$ Brix de las diferentes formulaciones de helados a base de leche de soya.

Con este análisis se determinó el contenido de sólidos solubles presentes en los diversos tratamientos del helado. Estrada (2019) indica que los obrix en los alimentos radica en la formulación, la cantidad de azúcar (sacarosa) presente en el producto, el cual da el sabor y cuerpo al helado. Obviamente el valor se puede regular agregando azúcar al producto. Por lo mencionado es importante conocer su contenido de dulzor ya que este influye directamente en las características organolépticas lo cual se determinó que el promedio mayor es el tratamiento LS4V $(20 \%$ leche de soya y $80 \%$ leche de vaca) con un promedio $31,67 \mathrm{y}$ el promedio menor es el tratamiento LS1V $(80 \%$ leche de soya y $20 \%$ leche de vaca) con un promedio 29,67. A diferencia de Cajas (2019) que presento valor de $8.025^{\circ}$ Brix en la mezcla de leche de soya con garbanzos siendo el contenido con más azúcar en la leche de soya.

\section{Acidez titulable}

En el análisis estadístico se determinó que si hay diferencia significativa entre los tratamientos LS4V ( $20 \%$ leche de soya y $80 \%$ leche de vaca) con el LS2V( $60 \%$ leche de soya y $40 \%$ leche de vaca), entre los tratamientos LS4V (20\% leche de soya y $80 \%$ leche de vaca) con el $\operatorname{LS} 1 \mathrm{~V}(80 \%$ leche de soya y $20 \%$ leche de vaca), entre los tratamientos LS3V ( $40 \%$ leche de soya y $60 \%$ leche de vaca $)$ con el LS2V $(60 \%$ leche de soya y $40 \%$ leche de vaca), entre los tratamientos LS3V (40\% leche de soya y $60 \%$ leche de vaca) con el $\operatorname{LS} 1 \mathrm{~V}(80 \%$ leche de soya y $20 \%$ leche de vaca) y entre los tratamientos LS2V (60\% leche de soya y $40 \%$ leche de vaca) con el tratamiento LS1V ( $80 \%$ leche de soya y $20 \%$ leche de vaca). Sin embargo, no hay diferencia significativa entre los tratamientos LS4V (20\% leche de soya y $80 \%$ leche de vaca) con el tratamiento LS3V ( $40 \%$ leche de soya y $60 \%$ leche de vaca).

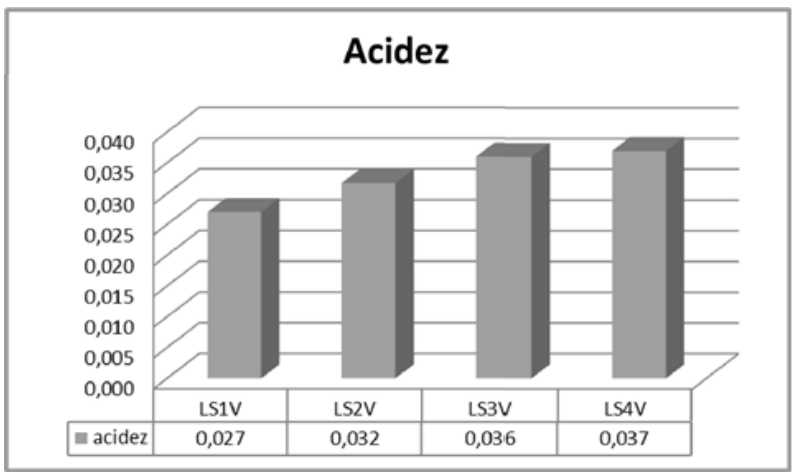

Gráfico 4. Acidez de las diferentes formulaciones de helados a base de leche de soya.

Se determinó la variable acidez para identificar los cambios producidos por diversos ingredientes como pulpa de mora, leche de soya y leche de vaca, crema de leche, etc. Además, Chacón et al. (2016) Mencionan que existe una interacción significativa entre el tipo de leche del helado siendo la interacción la combinación de los dos tipos de leche, que presentan características ácidas o alcalinas, y cuáles resultan neutros, ya que el balance ácido-alcalino del cuerpo es crítico para una buena salud. Ofreciendo un producto que favorezca a una dieta alimenticia sana para el organismo, a diferencia de lo que reporta Meza (2011) en la leche de soya con porcentaje alto de $\mathrm{pH} 0.437 \%$ debido a la combinación de los dos tipos de leche.

Indica Di Bartolo (2005), que el agregado de aire al helado es de una importancia fundamental para definir la calidad de un helado: Pues un agregado excesivo de aire dará un helado de baja calidad, sin cuerpo, deshaciéndose en la boca, dejando una leve sensación. Por el contrario, un helado con poco aire incorporado da una sensación pesada, muy fuerte que tampoco es deseable. Por lo descrito es importante la cantidad de aire que se le incorpora al helado porque si se obtiene un adecuado nivel de aire en la mezcla se logra obtener un buen coste de fabricación y ofrecer un producto de calidad al consumidor, en cuanto a lo que expresa Estrada (2019) en que el aumento del volumen del helado es debido al ingreso de aire en la mezcla, generando el efecto de la materia grasa y sólidos no lácteos.

Se consideró en el estudio la variable de sobreaumento en todos los tratamientos para identificar si el producto es rentable (Cuadro 2).

Cuadro 2. Valores de Sobreaumento del helado elaborado a base de leche de soya

\begin{tabular}{cccccc}
\hline \multicolumn{6}{c}{ Porcentaje de sobreaumento del helado a base de leche de soya y leche de vaca } \\
\hline Tratamientos & Litros de jarabe & Litros obtenidos & $\begin{array}{c}\text { Porcentaje de } \\
\text { overrum }\end{array}$ & $\begin{array}{c}\text { Porcentaje de } \\
\text { mezcla }\end{array}$ & Porcentaje de aire \\
\hline LS1V & 4 & 4.5 & $11 \%$ & $94,45 \%$ & $\mathbf{5 , 5 5 \%}$ \\
\hline LS2V & 4 & 6 & $33 \%$ & $83,33 \%$ & $\mathbf{1 6 , 6 7 \%}$ \\
\hline LS3V & 4 & 6.7 & $40,29 \%$ & $79,85 \%$ & $\mathbf{2 0 , 1 5 \%}$ \\
\hline LS4V & 4 & 7 & $42,86 \%$ & $78,57 \%$ & $\mathbf{2 1 , 4 3 \%}$ \\
\hline
\end{tabular}




\section{Elección del mejor tratamiento}

Una vez obtenido el mejor tratamiento mediante análisis sensorial y análisis físicos; se procedió a realizar los análisis físico-químicos, y microbiológicos al tratamiento LS4V $(20 \%$ leche de soya $+80 \%$ leche de vaca).

Cuadro 3. Resultados del mejor tratamiento

\begin{tabular}{lc}
\hline \multicolumn{1}{c}{ Parámetros } & Resultados \\
\hline $\mathrm{pH}$ & 5,05 \\
\hline Acidez & 0,037 \\
\hline Grados ${ }^{\circ}$ Brix & 31,67 \\
\hline Porcentaje de Sobreaumento & $42,86 \%$ \\
\hline Análisis Sensorial & 16 panelistas \\
\hline
\end{tabular}

No hay diferencia estadística significativa entre los tratamientos ya que los promedios indicaron que no hay un $\mathrm{pH}$ elevado a 6 ni inferior a 5 entre los diversos helados a base de leche de soya, así mismo, no hay un elevado porcentaje de solidos solubles entre ellas, sin embargo, hay una pequeña diferencia matemática en decimales.

\section{Análisis físico-químico del mejor tratamiento}

Se realizó análisis físico-químico al mejor tratamiento LS4V ( $20 \%$ leche de soya $+80 \%$ leche de vaca) en los días $1,10,20$ y 30 de almacenamiento.

\section{pH}

Como se observa en el gráfico 5 , obteniendo como $\mathrm{pH}$ inicial al primer día de estudio un valor de 5,05; a los diez días 5, 08; a los veinte días 5,21 y culminando a los treinta días un $\mathrm{pH}$ de 5,22. Esto quiere decir que con el pasar de los días su pH se volvía neutro, siendo un medio propenso para el crecimiento de los microorganismos, ya que ellos crecen con un $\mathrm{pH}$ entre 5 y 8 .

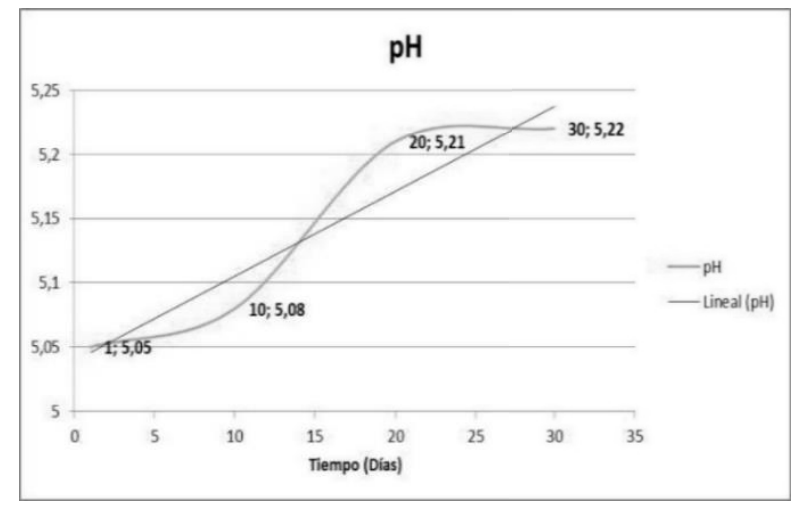

Gráfico 5. Resultados de $\mathrm{pH}$ del mejor tratamiento LS4V en los días de almacenamiento.

Menciona Chavarrías (2013), que los principales factores que afectan al crecimiento bacteriano son el tiempo, la temperatura, los nutrientes, el agua y el $\mathrm{pH}$. Siendo el $\mathrm{pH}$ la medida de acidez o alcalinidad de un alimento, un factor que es determinante para controlar el crecimiento bacteriano. Correlaciona Chavarrías (2010) que el pH de los alimentos es utilizado como un parámetro de calidad muy importante, ya que está íntimamente ligado con las características organolépticas, por lo que siempre debe ser evaluado debido a que suele registrar aumento en los días de estudios. Es por ello que se realizó un análisis de $\mathrm{pH}$ al mejor tratamiento LS4V (20\% Leche de soya $+80 \%$ leche de vaca), realizados cada 10 días durante el lapso de un mes. Por otro lado, Yépez (2015) menciona que el $\mathrm{pH}$ de una mezcla los helados deben tener valores de $\mathrm{pH}$ cercanos a 6.3 aproximadamente, por lo que la determinación de $\mathrm{pH}$ se convirtió en un parámetro fundamental estando dentro de los parámetros, ya que los valores de $\mathrm{pH}$ no controlados promueven el crecimiento bacteriano y de hongo, provocando grandes infecciones gastrointestinales en el consumidor y también la reducción del tiempo de vida útil de producto, ya que provoca desestabilización química en el mismo.

\section{Solidos solubles ( ${ }^{\circ}$ Brix)}

En el gráfico 6. Los datos de los ${ }^{\circ}$ Brix del tratamiento LS4V ( $20 \%$ de leche de soya y $80 \%$ leche de vaca), fueron medidos cada diez días de almacenamiento a una temperatura de $-15^{\circ} \mathrm{C}$ por un período de un mes. Dando como resultado e inicial $32^{\circ}$ Brix, a los 10 días de estudio $31^{\circ}$ brix, a los 20 días $30^{\circ}$ brix y finalmente al mes de su almacenamiento se mantuvo con $30^{\circ} \mathrm{Brix}$.

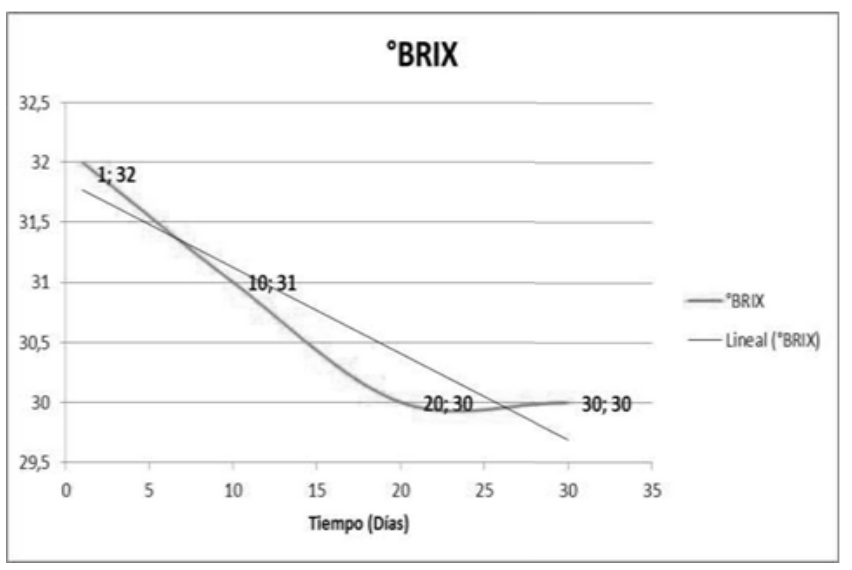

Gráfico 6. Grados ${ }^{\circ}$ Brix del mejor tratamiento LS4V en los días de almacenamiento.

Según Amado (2010) los ${ }^{\circ}$ Brix se generan por los azúcares de la leche, ayudando en la cristalización del helado obteniendo $16^{\circ}$ brix siendo este resultado menor a lo obtenido en el presente proyecto, en cuanto a lo que manifiesta Salazar y Zambrano (2015) obtuvieron 43- 52 ${ }^{\circ}$ Brix el cual se encuentra por encima a lo obtenido debido a la gran concentración generada por la temperatura sometida. 


\section{Acidez titulable}

En el gráfico 7 los resultados de acidez del helado de soya fueron medidos cada diez días después de su elaboración y almacenados a una temperatura de $-15^{\circ} \mathrm{C}$ por un tiempo de treinta días. Dando como resultado al día 1 fue de 0,036 almacenamiento, seguido al día 10 de 0,038; al día 20 de estudio es de 0,039 y al día 30 de estudio es de 0,40 . Estos resultados fueron calculados mediante el \% de ácido láctico.

\section{ACIDEZ}

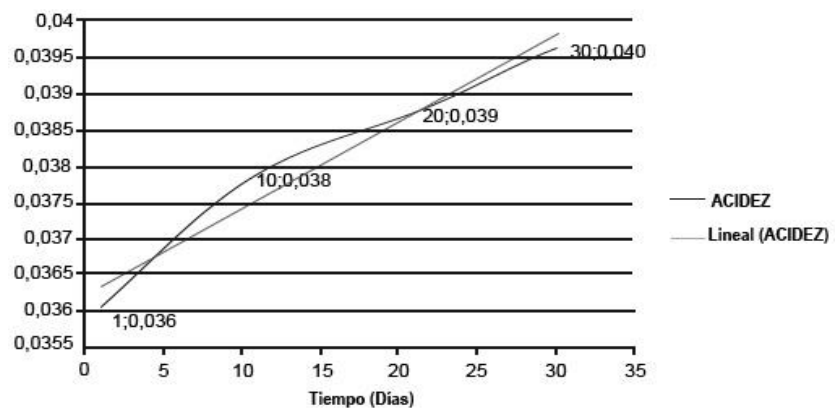

Gráfico 7. Resultados de acidez del mejor tratamiento LS4V en los días de almacenamiento.

La acidez obtenida en el tratamiento LS4V (20\% de leche de soya y $80 \%$ leche de vaca está por encima de lo permitido, de acuerdo a lo que indica la NTE INEN 0706 (2005) que la acidez óptima para el helado es de $0,25 \%$ y por lo tanto menciona Bejarano y Silva (2010) que la acidez determina el estado de conservación de un producto alimenticio. Un proceso de descomposición por hidrólisis, oxidación o fermentación, altera casi siempre la concentración hidrogeniónica.

\section{Composición Química}

En el cuadro 4 se observa los resultados de la composición química que se obtuvieron en el helado considerado como el mejor tratamiento. Obteniendo un porcentaje de 2,05 en proteínas, 2,78 en materia grasa, 28,50 de sólidos totales y un $29,17 \%$ de carbohidratos.

Cuadro 4. Resultados bromatológicos del mejor tratamiento LS4V

\begin{tabular}{lcc}
\hline \multicolumn{1}{c}{ Análisis } & Unidad & Resultados \\
\hline Proteínas & $\%$ & 2,05 \\
\hline Materia grasa & $\%$ & 2,78 \\
\hline Solidos Totales & $\%$ & 28,5 \\
\hline Carbohidratos & $\%$ & 29,17 \\
\hline
\end{tabular}

Mundo Heladero (2003), menciona que el helado juega un papel importante en la alimentación, desde el punto de vista nutricional, por ser un buen complemento en cualquier dieta alimenticia. Demostrando ser un producto de gran interés en persona que desean consumir un alimento que les ayude a nutrirlos sin tener que renunciar al placer de lo tradicional. Cumpliendo con lo establecido en las normas NTE INEN 0706 (2005) y presentando valores inferiores a los reflejados en la investigación de Rodríguez et al. (2010b).

\section{Análisis microbiológicos}

Para conocer la vida útil del producto, en cuanto a microorganismos, se realizó pruebas de mohos, levaduras, coliformes totales y recuento de mesófilos aerobios, durante los días 1,15 y 30 de almacenamiento.

\section{Análisis de mohos}

Se realizó un estudio de análisis de mohos para determinar si existía crecimiento del mismo, donde los datos resultaron ser bajos. Indicando que no hubo alteración en el producto por parte de mohos. Cumpliendo con lo establecido en las normas NTE INEN 0706 (2005), donde se permite $200 \mathrm{UFC} / \mathrm{g}$.

Cuadro 5. Resultado de análisis de mohos del mejor tratamiento LS4V en almacenamiento.

\begin{tabular}{|l|c|c|c|}
\hline Análisis & Día 1 & Día 15 & Día 30 \\
\hline Mohos & $<1 \times 10 \mathrm{UfC} / \mathrm{g}$ & $<1 \times 10 \mathrm{UfC} / \mathrm{g}$ & $<1 \times 10 \mathrm{UfC} / \mathrm{g}$ \\
\hline
\end{tabular}

Según Chavarrias (2013) el moho produce uno de los cambios más visibles en la descomposición de alimentos $y$, por otro lado, March (2018) indica que el crecimiento de moho en los alimentos muestra que un producto ya no es apto para el consumo humano, es casi imposible que una persona normal pueda distinguir entre los tipos inofensivos y los que son peligrosos para la salud. Es por esta razón que se debe evitar comer alimentos con moho, sobre todo si se encuentra en un alimento blando.

\section{Análisis de levaduras}

En el análisis realizado al mejor tratamiento se encontró que en el día 1 de almacenamiento existió una cantidad de 3,00 Log $10 \mathrm{UFC/g}$; transcurrido el tiempo al día 15 mostro 2,90 Log $10 \mathrm{UFC} / \mathrm{g}$ y terminando su periodo de estudio a los 30 días de almacenamiento varío a 2,95 Log $10 \mathrm{UFC} / \mathrm{g}$. Estos valores dieron a comprobar que la cantidad de levadura presente en el helado fue muy elevada, la cual pudo afectarse por la presencia de pulpa de mora.

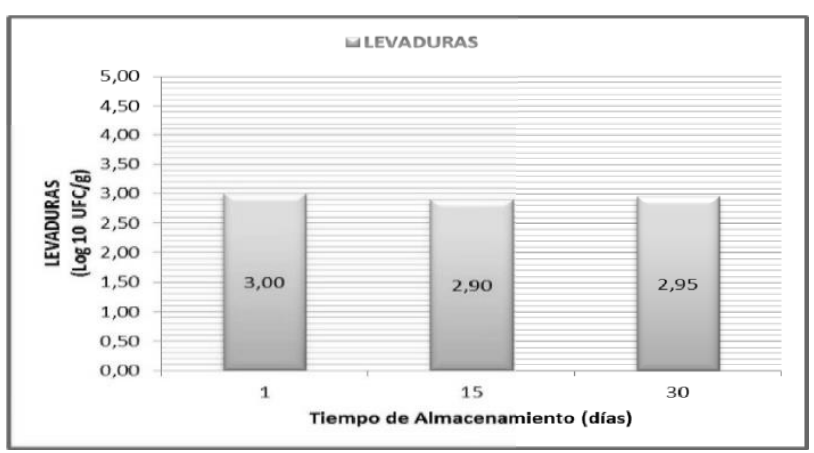

Gráfico 8. Resultado de análisis de levadura en UFC/g transformados a Log $10 \mathrm{UFC} / \mathrm{g}$ del mejor tratamiento LS4V en almacenamiento. 
Con estos resultados se determinó que la cantidad de levadura está por encima de lo establecido en la NTE INEN 0706 (2005). Pérez y Jiménez (2011) indica que las levaduras son microorganismos capaces de colonizar variados ambientes ricos en compuestos de carbono.

\section{Análisis de coliforme totales}

En el gráfico 9 se observa el resultado de los análisis de coliformes totales de la muestra del mejor tratamiento. Estos resultados fueron dados en $\mathrm{UFC} / \mathrm{g}$ y transformados a Log $10 \mathrm{UFC} / \mathrm{g}$. Estos datos descienden con el transcurso del período de almacenamiento, que al día 1 tuvo una cantidad de 2,04 Log $10 \mathrm{UFC} / \mathrm{g}$, al día 15 bajo a 2,00 Log $10 \mathrm{UFC/g}$ y culminando el día 30 de estudio se obtuvo un valor de $1,95 \mathrm{Log} 10 \mathrm{UFC} / \mathrm{g}$.

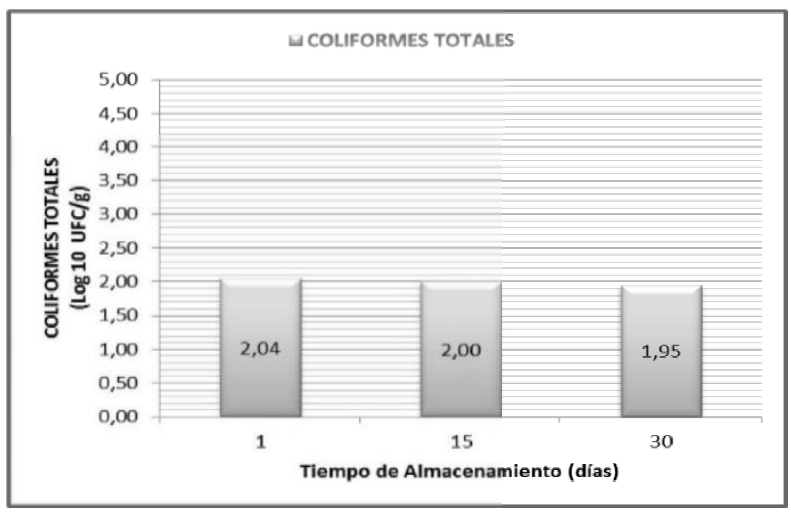

Gráfico 9. Resultados de análisis de coliformes totales del mejor tratamiento LS4V en los días de almacenamiento.

Estos resultados se encuentran dentro de la NTE INEN 0706 (2005) los cuales son aceptados. Señala Rosales y Díaz (2006) que los coliformes constituyen un grupo bacteriano heterogéneo, con especies de origen intestinal y no intestinal y menciona Ávila y Silva (2010) que las bacterias coliformes son utilizadas como parámetro indicador de la calidad higiénico-sanitaria en productos procesados, los cuales se destruyen fácilmente por el calor y pueden morir por congelación de almacenamiento, presentando el mismo caso de ausencia, en la investigación de Goma, et al (2017).

\section{Recuentos aerobios}

Los análisis microbiológicos de recuentos aerobios se efectuaron los días 1,15 y 30 de almacenamiento para comprobar la existencia y cantidad microbiana presente en el mismo y su variación en el transcurso del tiempo. Como dato inicial al día 1 se presentó con 3,60 Log 10 $\mathrm{UFC} / \mathrm{g}$; pero al día 15 disminuyo la cantidad de mesófilos aerobios a 2,30 Log $10 \mathrm{UFC} / \mathrm{g}$, esto se debe por la falta de oxígeno y como último resultado al día 30 se obtuvo 3,54 Log $10 \mathrm{UFC} / \mathrm{g}$.
Ramírez (2011) indica que la falta de crecimiento de los mesófilos aerobios a temperaturas bajas es por la reducción de la velocidad de las reacciones bioquímicas y al cambio de estado de los lípidos de la membrana celular que pasan de ser fluidos a cristalinos impidiendo el funcionamiento de la membrana celular en los días 1, y 15 a diferencia del día 30 que se encontró dentro de los parámetros por lo establecido en la NTE INEN 0706 (2005).

\section{Análisis económico}

Se llevó a cabo el análisis de costo al mejor tratamiento LS4V ( $80 \%$ leche de vaca $+20 \%$ leche de soya), el cual fue elegido por medio de análisis sensorial. El rendimiento que se obtuvo en este tratamiento fue de 7 litros de helado con leche de soya con una cantidad de 4 litros de mezcla.

Los precios y cantidad requerida para la elaboración del helado se detallan a continuación en el cuadro 5, donde se determinó que el costo de este tratamiento es de 7,98, y el valor por cada litro obtenido es de $\$ 1,14$.

Cuadro 5. Costos de elaboración de helado a base de soya por tarrina de 7 litros.

\begin{tabular}{ccccc}
\hline Ingredientes & $\begin{array}{c}\text { Unid } \\
\text { ad }\end{array}$ & $\begin{array}{c}\text { Costo } \\
\text { unitarios }\end{array}$ & $\begin{array}{c}\text { Cantidad } \\
\text { utilizada }\end{array}$ & Precio \\
\hline Leche de soya & $\mathrm{L}$ & 2,00 & 0,5 & $\mathbf{1 , 0 0}$ \\
\hline Leche de vaca & $\mathrm{L}$ & 1,30 & 1,5 & $\mathbf{1 , 9 5}$ \\
\hline $\begin{array}{c}\text { Leche } \\
\text { evaporada }\end{array}$ & $\mathrm{ml}$ & 0,0054 & 100 & $\mathbf{0 , 5 4}$ \\
\hline $\begin{array}{c}\text { Crema de } \\
\text { leche }\end{array}$ & $\mathrm{L}$ & 4,60 & 0,2 & $\mathbf{0 , 9 2}$ \\
\hline Pulpa de mora & $\mathrm{L}$ & 2,00 & 0,5 & $\mathbf{1 , 0 0}$ \\
\hline Saborizante & $\mathrm{gr}$ & 0,003 & 4,7 & $\mathbf{0 , 0 1}$ \\
\hline Azúcar & $\mathrm{Kg}$ & 2,00 & 1 & $\mathbf{2 , 0 0}$ \\
\hline $\begin{array}{c}\text { Leche en } \\
\text { polvo }\end{array}$ & $\mathrm{Gr}$ & 0,008 & 60 & $\mathbf{0 , 4 8}$ \\
\hline Estabilizante & $\mathrm{Gr}$ & 0,012 & 7 & $\mathbf{0 , 0 8}$ \\
\hline Costo Total & & & & $\mathbf{\$ 7 , 9 8}$ \\
\hline
\end{tabular}

\section{CONCLUSIONES}

El tratamiento LS4V $(20 \%$ leche de soya $+80 \%$ leche de vaca) presentó mayor aceptación en el análisis sensorial y parámetros de análisis físico-químicos aceptables de acuerdo a las Normas NTE INEN 0706 vigentes en la calidad del helado, además fue el más rentable, con un costo de producción de $\$ 1,14$ dólares por litro, proporcionando al productor más rentabilidad y al consumidor un helado más barato y nutritivo. Resulta necesario evaluar el posible efecto benéfico a la salud, para poder considerarlo como alimento funcional.

\section{LITERATURA CITADA}

Amado, E. 2010. Formulación y evaluación sensorial del helado de maracuyá elaborado con leche de soya. Tesis 
de grado. Universidad Autónoma Agraria "Antonio Narro". Departamento de ciencia y tecnología de alimentos. Buenavista-Mexico. 1-41.

Ávalos, R. 2018. Evaluación de dos emulsificantes y tres proporciones de mezclas de helado y yogur en las propiedades fisicoquímicas y sensoriales de helado de yogur sabor café. Tesis de grado. Escuela Agrícola Panamericana. Zamorano-Honduras. 1-24.

Ávila, V. \& Silva, M. 2010. Evaluación de la calidad microbiológica de los helados elaborados en una empresa del municipio Soacha y su impacto a nivel local. Tesis de grado. Pontifica Universidad Javeriana. Facultad De Ciencias. Bogotá-Colombia. 16-101.

Bejarano, A., \& Silva, A. 2010. Estabilidad del helado de crema de leche. Tesis de grado. Escuela Superior Politécnica Litoral. Instituto De Tecnologías. Guayaquil-Ecuador. 1-34.

Benítez, J. 2006. Estudio de la soya, derivados, efectos en la alimentación y propuesta gastronómica. Tesis de Grado. Universidad Tecnológica Equinoccial. Facultad: Ciencias Sociales y Comunicación. QuitoEcuador. 1-95.

Cajas, J.2019. "Evaluación de las características de bebidas de Glycine max (SOYA), Cicerarietinum (garbanzo) con la adición de Aloe Barbadensis Miller (sábila) como alternativa nutricional". Tesis de grado. Universidad Técnica Estatal De Quevedo. Facultad De Ciencias De La Ingeniería. Los ríos-Ecuador. 1-75.

Chacón, V. A, Pinela, C. M. \& Jiménez, G. C. 2016. Características fisicoquímicas y sensoriales de helados de leche caprina y bovina con grasa vegetal. Agron. MesoamVol. 27 (1) 19-36.

Chavarrías, M. 2010. Determinación del tiempo de la vida útil de la leche de soya mediante un estudio de tiempo real. Tesis de grado. Escuela Superior Politécnica Del Litoral. Programa De Especialización De Tecnología En Alimentos. Guayaquil-Ecuador. 1-53.

Chavarrías, M. 2013. pH de los alimentos y la seguridad alimentaria. Fundación eroski. Eroski consumer. 1-2.

Constante, P. 2012. "Elaboración y conservación de leche y yogurt de soya utilizando métodos combinados en la planta de lácteos de la Universidad Estatal De Bolívar" Tesis de grado. Universidad Estatal De Bolívar. Facultad de Ciencias Agropecuarias, Recursos Naturales y del Ambiente. Guaranda-Ecuador. 4-87.

Di Bartolo, E. 2005. Guía para la elaboración de helados. Scrib.https://es.scribd.com/document/169578158/Gui a-Para-La-Elaboracion-d-Helados. 1-57.
Estrada, M. 2019. Desarrollo a escala laboratorio de un helado deslactosado con evaluación de sus características sensoriales, nutricionales y microbiológicas. Tesis de maestría. Universidad de San Carlos de Guatemala. Facultad de Ingeniería. Guatemala. 1-64.

Farías, D. 2017. "Plan de negocios para la creación de "nutrí-soya" emprendimiento para la comercialización de helados a base de leche de soya en la cdla. La garzota en la ciudad de Guayaquil". Tesis de grado. Instituto Superior Tecnológico Sudamericano (TECSU) De Guayaquil. Guayaquil-Ecuador. 1-68.

Goma, M. SH.;Abdel-Aziz, M. E.;Abdel-Salam, A. 2017. Effect of total and partial replacing the Milk Powder Used in the Made of Ice Cream by the Whey Protein Concentrate and Soy flour on Product Quality. Journal of Food (10) 8. 395-400.

Gómez, F. 2011. "Investigación del Tofu y elaboración de nuevas alternativas gastronómicas en la repostería". Tesis de grado. Universidad Tecnológica Equinoccial Facultad De Turismo Y Preservación Ambiental, Hotelería Y Gastronomía. Quito-Ecuador. 1-152.

González, J. 2011. "Elaboración y evaluación nutricional de una de bebida proteica a base de lactosuero y chocho (Lupinus mutabillis) como suplemente alimenticio". Escuela superior politécnica de Chimborazo. Facultad de Ciencias. RiobambaEcuador. 1-89.

ISO 3728. 2004. Norma internacional. Milk and milk products. Determinación de solidos totales.

ISO 4832. 2006. Norma internacional. Microbiología de alimentos y alimentos para alimentación de animales método horizontal para la enumeración de coliformes - técnica de conteo de colonias.

ISO 4833. 2003. Norma internacional. Milk and Milk Products. Recuento de microorganismos mesófilos.

ISO 6611. 2004. Norma internacional. Milk and milk products. Enumeration of colony-forming units of yeasts and/or mould. Colony Count technique at 25 degree $\mathrm{c}$.

March, A., Gonzáles, J. \& Tabera, A. 2018. Evaluación de la calidad microbiológica de una planta elaboradora de helado industrial de Tandil. Tesis de grado. Facultad de Ciencias Veterinarias - UNCPBA-. Buenos airesArgentina. 1-42.

M'Boumba, A. Rodríguez, T., Cainejo, J. 2009. Formulación de un helado a partir de leche de soya. Ciencia y Tecnología de los Alimentos. (2) 19 . 15-19 
Meza, J. 2011. Proceso de elaboración de helados con leche de soya (Glycine max (L) merril) saborizado con pulpa de arazá (Eugenia stipitata). Tesis de grado. Universidad Tecnica Estatal De Quevedo. Unidad De Estudios A Distancia-Modalidad Semipresencial. Los ríos-Ecuador. 1-66.

Miranda, C., Miranda, R., Pilamala, A., Molina, J., Cerda, L. 2019. El sector hortofrutícola de Ecuador: Principales características socio-productivas de la red agroalimentaria de la uvilla (Physalis peruviana). Ciencia y Agricultura. Colombia. 31-51.

Mundo Heladero. 2003. El helado como alimento. Vilbo Ediciones.1-5.

NTE INEN 0014. 1984. Normas Técnicas Ecuatorianas. Leche determinación de solidos totales y ceniza.

NTE INEN 0016. 1984. Normas Técnicas Ecuatorianas. Leche determinación de proteínas.

NTE INEN 0706. 2005. Normas Técnicas Ecuatorianas. Helados. Requisitos.

NTE INEN 1 529-11. 1998. Normas Técnicas Ecuatorianas. Control microbiológico de los alimentos. Determinación de la presencia o ausencia de mohos y levaduras (utilizando medio liquido).

NTE INEN 1529-5. 2006. Control microbiológico de los alimentos. Determinación de la cantidad de microorganismos aerobios mesófilos. REP.

NTE INEN 1529-7. 2013. Control microbiológico de los alimentos. Determinación de microorganismos coliformes por la técnica de recuento de colonia.

Pérez, N. \& Jiménez, E. 2011. Producción de metabolitos secundarios de plantas mediante el cultivo in vitro. Rev. Biotecnología Vegetal. (4)11. 195.

Ramírez, O. 2011. Factores que afectan a la supervivencia de los microorganismos en los alimentos. Tesis de grado. Universidad pública de Navarra. NavarraEspaña.

Rosales, Y., \& Díaz, C. 2006. Evaluación De La Calidad Microbiológica De Helados Caseros En Merida/ Venezuela. Rev. Salud pública y nutrición. (3) 7.
Rodríguez, T., Camejo, J., M'Boumba, A., Roger, V. 2010a. Utilización de leche de soya en helado. Ciencia y Tecnología de los Alimentos. (1) 20. 27-30.

Rodriguez, T. \& Camejo, J. \& Rodríguez, Aniely \& Hombre, R. \& Nuñez de Villavicencio, Margarita. 2010.b. Utilization of powdered soy milk in ice cream. Ciencia y Tecnología de Alimentos. 20. 27-30.

Salazar, C. 2012. "Plan de negocio para la sustentabilidad de un nuevo emprendimiento: productora $\mathrm{y}$ comercializadora de leche de soya" para la ciudad de quevedo, periodo 2012. Tesis de grado. Universidad Técnica Estatal De Quevedo. Facultad De Ciencias Empresariales. Quevedo-Ecuador. 1-104.

Salazar, J. \& Zambrano, F. 2015. Tipo de edulcorante en la elaboración de manjar de soya y características sensoriales del producto. Tesis de grado. Universidad Laica Eloy Alfaro De Manabí Extensión Chone. Manabí-Ecuador.1-53.

Sancho, J., Bota, E., \& De Castro, J. 1999. Introducción al. Barcelona: Edicions Universidad de Barcelona. 120 .

Sharma, H.K. \& Singh, Charanjiv \& Sarkar, B.C. \& A, Shitandi. 2009. Quality of soft-serve ice-cream prepared from incorporation of soy milk. Journal of Food Science and Technology. 46. 172-173.

Tripathi, A.K., Misra, A.K. 2005. Soybean A consummate functional food: A review. Journal of Food Science and Technology. (2)42. 111-119.

Tobar, D. 2008. Determinación y comparación de proteínas y grasas de la leche de soya, elaborada tanto artesanal como industrialmente, comercializada en el Departamento de Guatemala, Guatemala. Tesis de grado. Universidad De San Carlos De Guatemala Facultad De Ciencias Químicas y Farmacia. Guatemala. 9-46.

Villalobos, A., Pineda, A., Jiménez C. 2016. Características físicoquímicas y sensoriales de helados de leche caprina y bovina con grasa vegetal. Agronomía Mesoamericana. Costa Rica. (27) 1.

Yépez, E. 2015. Utilización de suero lácteo en polvo en mezclas base para helados con pulpa de mora. Tesis de grado. Universidad tecnológica equinoccial. Facultad de ciencias de la ingeniería. Quito-Ecuador. 1-5 